\title{
Risk factors for postpartum intrauterine device expulsion among women delivering at a tertiary Hospital in Uganda: a prospective cohort study
}

\author{
Joy Muhumuza ${ }^{1,2}$, Richard Migisha ${ }^{3 *}$ (D) Joseph Ngonzi ${ }^{1}$, Musa Kayondo ${ }^{1}$ and Godfrey Mugyenyi ${ }^{1}$
}

\begin{abstract}
Background: Postpartum intrauterine device (PPIUD) use refers to intrauterine device (IUD) insertion after delivery but within $48 \mathrm{~h}$ of birth. In Uganda, the general use of modern methods of contraception is low with < $1 \%$ of the women adopting the IUD as a method of contraception. An important limiting factor to increased uptake of immediate postpartum IUD insertion may be its expulsion rates which vary widely. There is minimal documentation PPIUD expulsion rates and factors associated with PPIUD expulsion during puerperium in Uganda.

Objective: We aimed to determine the proportion of TCu380A (copper) intrauterine devices expelled by 6 weeks postpartum, and identify risk factors for expulsion among women delivering at Mbarara Regional Referral Hospital $(\mathrm{MRRH})$ in southwestern Uganda.

Methods: We conducted a prospective cohort study from September 1, 2014 to January 31, 2015 at MRRH. We administered a structured questionnaire to all participants, to capture data on their baseline demographic, clinical and obstetric characteristics. We followed up women who accepted the PPIUD insertions at 6 weeks post insertion for any IUD expulsion. We fit multivariable log binomial regression models to identify risk factors for IUD expulsion.

Results: We enrolled 167 women who had PPIUDs inserted. Of the144 women who returned at 6 weeks for follow up, 13 (9\%; 95\%Cl:4.9-15\%) of them had the IUDs expelled. In the multivariable model, the significant risk factors for PPIUD expulsion were: IUD insertion more than 10 min post-delivery (aRR 8.1,95\% CI 1.26-51.98, $p=0.027$ ) and bloody lochia flow of $\geq 15$ days (aRR 8.5, 95\%Cl 1.47-48.47, $p=0.017$ ).

Conclusion: The cumulative expulsion rate of postpartum IUDs among women delivering at MRRH was low and comparable to expulsion rates in interval insertions. Longer duration from delivery to IUD insertions and longer duration of bloody lochia flow were key risk factors for postpartum IUD expulsion. More emphasis should be put on prenatal counseling for postpartum family planning to allow for postplacental IUD insertions, which are associated with lower expulsion rates.
\end{abstract}

Keywords: Copper intrauterine device, Intrauterine device, Intrauterine device expulsion, Postpartum contraception, Postpartum intrauterine device, Postplacental intrauterine device, TCu380A intrauterine device

\footnotetext{
* Correspondence: migisha85@gmail.com

${ }^{3}$ Department of Physiology, Mbarara University of Science and Technology,

P.O Box 1410, Mbarara, Uganda

Full list of author information is available at the end of the article
}

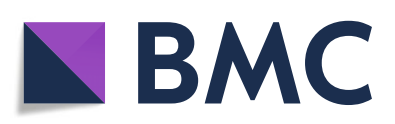

(- The Author(s). 2021 Open Access This article is licensed under a Creative Commons Attribution 4.0 International License, which permits use, sharing, adaptation, distribution and reproduction in any medium or format, as long as you give appropriate credit to the original author(s) and the source, provide a link to the Creative Commons licence, and indicate if changes were made. The images or other third party material in this article are included in the article's Creative Commons licence, unless indicated otherwise in a credit line to the material. If material is not included in the article's Creative Commons licence and your intended use is not permitted by statutory regulation or exceeds the permitted use, you will need to obtain permission directly from the copyright holder. To view a copy of this licence, visit http://creativecommons.org/licenses/by/4.0/ The Creative Commons Public Domain Dedication waiver (http://creativecommons.org/publicdomain/zero/1.0/) applies to the data made available in this article, unless otherwise stated in a credit line to the data. 


\section{Introduction}

Globally, approximately 220 million women in need of modern family planning methods are unable to access them for various reasons [1, 2]. The unmet need for family planning in sub-Saharan Africa, including Uganda is still very high (25 and 34\% respectively) [3-5]. Across sub-Saharan Africa and Uganda, the IUD remains underutilized with just 1 and $0.5 \%$ of married women using it, respectively $[5,6]$. The intrauterine device (IUD) is a highly effective, safe, reversible and longacting type of contraception [7]. The CuT380A device is the most effective of IUDs with failure rate of $0.6-0.8$ pregnancies per 100 women in the first 12 months of use and has the lowest cumulative pregnancy rate $(2.2$ per 100 women after 8 years) [8]. Postpartum intra uterine device (PPIUD) insertion bridges the limitations to the unmet family planning need by promoting IUD use. Offering postpartum insertions is one of the reasons for high uptake of the IUD in countries like China, Egypt, Mexico and Turkey where the IUD is the most popular reversible method of contraception [9]. The unique advantage of postpartum intrauterine contraception is that contraception is initiated early with a very low failure rate. Insertion of an IUD immediately after delivery has been recommended by WHO, as one of the safest and most effective method of reversible contraception for postpartum women who wish to either space or limit births, whether they are breastfeeding or not [8].

In Uganda, 25\% of total births are less than 2 years apart [5], yet birth spacing is an important maternal and child health intervention [10]. For women with limited access to medical care, the time of delivery offers a unique opportunity to address their need for contraception if the delivery takes place in a healthcare facility. In addition, PPIUD may help avoid the discomfort related to interval insertion since insertion complaints caused by bloody lochia and cramping are masked [11]. Furthermore, effective utilization of family planning could avert approximately $32 \%$ of maternal deaths worldwide, by avoiding unintended premature pregnancies and abortions [12]. As previously reported [13], optimal utilization of modern contraceptive methods could result in approximately $85 \%$ decline in induced abortions in Uganda. In the immediate post-partum period, women are highly motivated to take up an effective contraception, as opposed to waiting for 6 weeks to initiate effective contraception. On the contrary, if the women are left to wait, they may conceive unintentionally or may not even return for contraception [14]. Appropriate times for IUD insertion in the immediate postpartum period include the postplacental (within $10 \mathrm{~min}$ after expulsion of the placenta), the immediate postpartum (within $48 \mathrm{~h}$ of delivery) and trans-cesarean IUD insertion (during a cesarean delivery), before the uterine incision is sutured.
An important limiting factor to increased uptake of immediate PPIUD insertion may perhaps be due to its expulsion rates, that range from as low as $5 \%$ to as high as $70[15,16]$. Indeed, there has been skepticism in the recent past about PPIUD among some healthcare professionals with regard to the variable complication and expulsion rates cited in literature [1, 17]. Previous studies have found several factors to be associated with PPIUD expulsion, including: age [18], parity [19], mode of delivery [20] and timing of insertion [21]. There is minimal documentation on expulsion rates and risk factors of PPIUD expulsion in Uganda. In this prospective cohort study, we sought to determine the expulsion rate of PPIUD at 6 weeks postpartum and risk factors for PPIUD expulsion, among women delivering at Mbarara Regional Referral Hospital (MRRH), southwestern Uganda.

\section{Methods \\ Study site and setting}

We conducted a prospective cohort study from September 1, 2014 to January 31, 2015 at the maternity ward (labor, postnatal and operating theatre sections) of Mbarara Regional Referral Hospital (MRRH) in southwestern Uganda. The hospital serves as a referral centre for other ten district hospitals within the south-western region. The maternity ward of MRRH records approximately 10,223 total deliveries annually, with an average of 20-25 vaginal deliveries daily and a caesarean section rate of $30 \%$. The hospital also has a family planning clinic which offers contraceptive services to an estimated 993 women annually and about 3\% of these women take up interval IUD [22].

\section{Study population}

Our study participants were women who delivered at MRRH (both vaginal and cesarean deliveries) during the 5 months' study period, that fulfilled the inclusion criteria. We included women who met the WHO medical eligibility for PPIUD insertion [8], resided in Mbarara municipality (within $30 \mathrm{~km}$ radius), consented to participate in the study, and were willing to return at 6 weeks post IUD insertion for follow up. We excluded women with any of the following medical conditions: altered level of consciousness, post-partum hemorrhage (PPH), temperature $>38^{\circ} \mathrm{C}$ during or after labor, pre-labor rupture of membranes $>18 \mathrm{~h}$, obstructed labor, and uterine fibroids or malformations.

\section{Study procedures and sampling}

We employed consecutive sampling technique to recruit eligible participants. We assessed eligibility by checking medical records of all women in early labor and those who had delivered vaginally a night before, to ascertain 
eligible participants without contraindications to PPIUD insertion, as well as checking the place of residence. We introduced the study to eligible participants through family planning health talks held daily on the maternity ward as part of routine practice.

Each eligible woman received individual counseling session about postpartum contraception where IUD was highlighted together with other options that included: mini-pills, bilateral tubal ligation, implants, lactation amenorrhea method and condoms. This enabled the women to make a voluntary and informed choice. The merits of each method, their common side effects and possible complications were explained comprehensively. Eligible participants were then approached individually to obtain an informed consent. Upon consent, the IUD was inserted within $48 \mathrm{~h}$ of delivery. Those who opted for an alternative method were referred to the family planning clinic at MRRH to receive the methods of their choice.

We used the following study instruments: a screening tool, a structured questionnaire and a PPIUD follow up card and form. We used the screening tool to counter check the eligibility of the women and to exclude those with contraindications to PPIUD insertion. We administered a structured questionnaire to capture data on socio-demographic, clinical and obstetric characteristics of the participants, including their data on family planning and gynecological history. The study participants were given health education on how best to recognize expulsions for example through the string length or even vivid expulsion, postpartum warning signs like bright red bleeding for which the woman needed to change her pad more than six times a day, unusual abdominal or pelvic pain (not after-birth pain) and unusual vaginal discharge or pain. The PPIUD follow-up card contained information on the date of insertion and follow up visit, date of removal of the IUD, the telephone number of the principal investigator and one of the research assistants. We used the PPIUD follow-up form to assess the postnatal experiences of the participants and it was filled at the follow-up visit. The follow up form was filled by asking questions and performing clinical examination. A speculum examination was then performed to check if the strings were visible or not and any discharge noted. The visible IUD strings were trimmed at approximately 3-5 cm. Participants whose strings were invisible at the cervical opening (os) and had not reported vivid IUD expulsion were sent for a uterine ultra sound scan to confirm expulsion. We assessed the study participants in whom the PPIUDs were inserted before discharge for comfort and followed them up at 6 weeks for expulsion. We emphasized the need for review at 6 weeks postinsertion. Participants were advised to call or comeback (any time before the set follow-up date) in case of any concern about the method. At 6 weeks, speculum or digital vaginal examination and/or abdominal/pelvic ultra sound scan were used to confirm IUD presence or expulsion. In addition, string shortening was done at the follow up visit.

\section{IUD insertion technique}

All necessary instruments (CuT380A, sterile ring forceps, Sims speculum, povidone- iodine, kidney dish, head lamp and gauze pieces) were prepared. Infection prevention protocols were observed at all times by use of sterile equipment and the insertion was performed by a trained healthcare professional (midwife or medical doctor) using ring forceps. The IUD was inserted to the uterine fundus as confirmed by palpation with a hand placed on the abdomen overlying the fundus. The cervical os was then gently inspected with the Sims speculum for strings before the participant left the procedure room. To ensure data quality control, all the healthcare professionals involved in IUD insertion had undertaken a training program on PPIUD and interval IUD insertion by Population Services International (PSI) and Marie stopes International (MSI) and were certified competent. In addition, every 10th PPIUD insertion was supervised by a consultant Obstetrician/gynecologist.

\section{Study variables}

Our primary outcome variable was IUD expulsion by 6 weeks post insertion. The independent variables were: socio-demographic factors (age, marital status, tribe, religion, level of education and occupation), obstetric and gynecologic factors (parity, birth weight of baby, duration of labor, mode of delivery, time lag from delivery to IUD insertion, menstrual flow and history of IUD expulsion), and postnatal factors (severe cramps in puerperium, resumption of sexual intercourse, breastfeeding, excessive vaginal bleeding in puerperium, use of herbs, douching, tummy tying, return of menses and heavy physical activity).

\section{Sample size and data analysis}

We computed the sample size using the Fleiss formula for unmatched cohort studies, with the following assumptions: power of $80 \%$, percentage of exposed with outcome of $25.9 \%$ and percentage of unexposed with outcome of $14.3 \%$, based on the Mexican prospective cohort study where $25.9 \%$ of women who were multiparous expelled the PPIUD and $14.3 \%$ of primeparas expelled the PPIUD [19]. This gave a total sample size of 170 participants, after inflation for $10 \%$ loss to follow-up.

We entered data in EpiData (EpiData, Odende, Denmark) and later exported to Stata (StataCorp, College Station, Texas, USA) for analysis. We described 
baseline socio-demographic, obstetric, gynecological and clinical characteristics of participants. We determined the expulsion rate as the cumulative incidence by dividing the number of women who had the IUDs expelled by total number of women who came for follow up and expressed as a percentage. To determine the risk factors for expulsion of IUD, we performed univariable and multivariable analysis, using log binomial regression analysis. Our measure of association was risk ratios (RRs). All factors with $p$-value $<0.2$ in univariable models were included in the multivariable models through backward stepwise method to determine the adjusted risk factors for PPIUD expulsion. Corresponding adjusted risk ratios (aRRs) and their $95 \%$ confidence intervals were reported. Risk factors were considered significant at a $p$-value of $<0.05$.

\section{Results}

Of 324 women who received health education, we present results for 167 women who were enrolled into the study. The various reasons for non-participation into the study are depicted in Fig. 1.

\section{Baseline characteristics of study participants}

Of the 167 study participants, most were aged 25-34 years (53.9\%), married (91\%), housewives (50.9\%), had some formal education (94.6\%) and were Christian (89.7\%) (Table 1).

The majority of the participants were multiparas (84.4\%), had delivered vaginally $(74.9 \%)$ and had live babies (99.3\%) with a mean birth weight of $3.3 \mathrm{~kg}$ (SD \pm 0.6). Seventy-five participants $(45.2 \%)$ had IUD inserted within $10 \mathrm{~min}$ of delivery. Only eleven participants
(6.6\%) had ever used IUD for family planning and the mean duration of use was $4.0(\mathrm{SD} \pm 1.9)$ years.

Postnatal characteristics of the 144 participants who returned for follow-up are presented in Table 2 . About half (51.4\%) of the study participants had resumed sexual activities by the time of review; $9 \%$ of the participants had returned their menses by 6 weeks' post- delivery. Few (12.5\%) participants had resumed heavy physical activity by 6 weeks' postpartum. History of herbal medicine use was reported in $15.3 \%$ of the study participants.

\section{Expulsion rate of PPIUD by 6 weeks post-insertion}

Among the 144 participants who had PPIUDs inserted, 13 had them expelled by 6 weeks post-insertion, for an expulsion rate of $9 \%$ (95\%CI:4.9-15\%), as seen in Fig. 1. Of the 13 participants who had PPIUD expelled, two (15.4\%) had complete expulsion of the IUD within 2 weeks of insertion, while the remaining 11 (84.6\%) had their IUDs partially expelled (with IUD stem visualized at the external cervical os on speculum exam) at 6 weeks (Fig. 1).

\section{Risk factors for PPIUD expulsion}

The results for univariable and multivariable analysis for the risk factors for PPIUD expulsion are presented in Table 3. In the multivariable model, the significant risk factors for PPIUD expulsion were: IUD insertion between 11 and $59 \mathrm{~min}$ after delivery (aRR 8.11, 95\%CI: 1.26-51.98, $p=0.027$ ) and duration of bloody lochia flow> 15 days (aRR 8.45, 95\%CI: $1.47-48.47, p=0.017$ ).

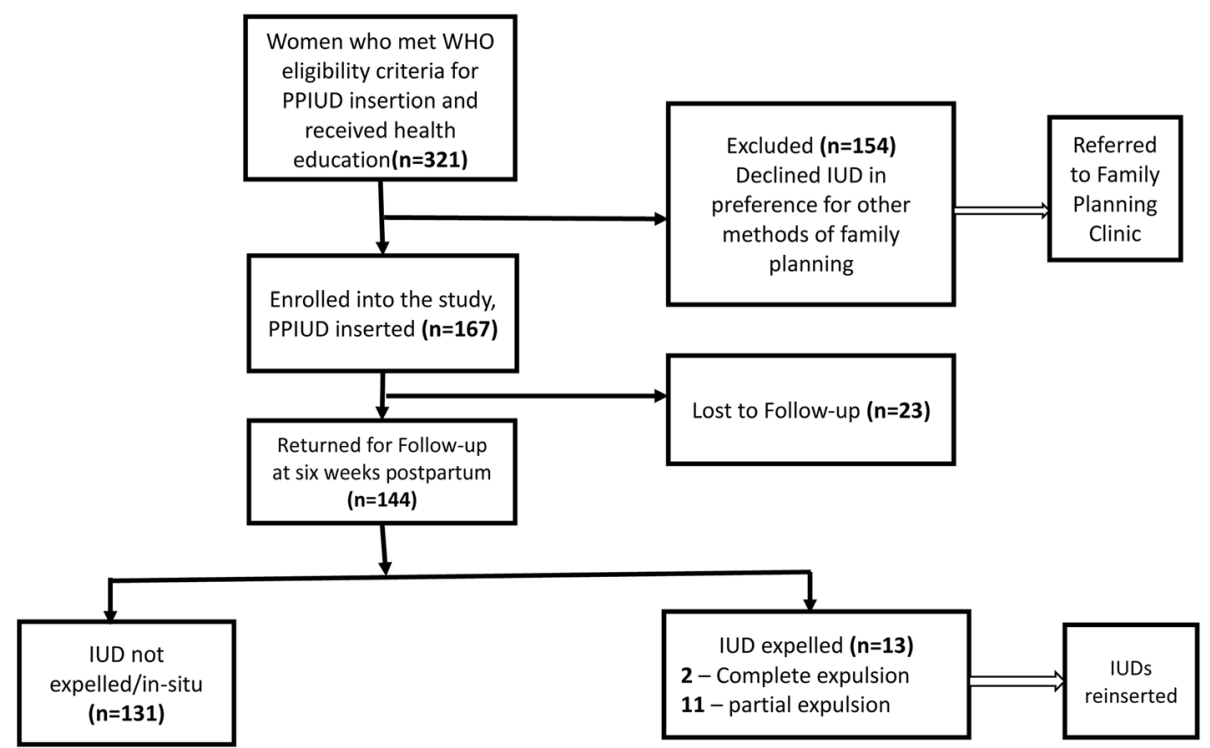

Fig. 1 Flow diagram showing recruitment, enrollment and Intrauterine device (IUD) status at follow up of study participants 
Table 1 Baseline Socio-demographic and obstetric Characteristics of study participants $(N=167)$

\begin{tabular}{|c|c|c|}
\hline Characteristics & Frequency (n) & Percentage (\%) \\
\hline \multicolumn{3}{|l|}{ Age } \\
\hline $18-24$ & 44 & 26.3 \\
\hline $25-34$ & 90 & 53.9 \\
\hline$>=35$ & 33 & 19.8 \\
\hline \multicolumn{3}{|l|}{ Education } \\
\hline None & 9 & 5.4 \\
\hline Primary & 64 & 38.3 \\
\hline Secondary & 55 & 32.9 \\
\hline Tertiary & 39 & 23.4 \\
\hline \multicolumn{3}{|l|}{ Marital Status } \\
\hline Single /Divorced & 15 & 9 \\
\hline Married & 91 & 91 \\
\hline \multicolumn{3}{|l|}{ Parity } \\
\hline One & 26 & 15.6 \\
\hline Two & 30 & 18 \\
\hline Three & 34 & 20.4 \\
\hline Four & 18.5 & 18.5 \\
\hline Five \& above & 46 & 27.5 \\
\hline \multicolumn{3}{|l|}{ Mode of delivery } \\
\hline Vaginal & 125 & 74.9 \\
\hline Caesarean section & 42 & 25.1 \\
\hline \multicolumn{3}{|c|}{ Baby condition at birth } \\
\hline Alive & 166 & 99.3 \\
\hline Stillbirth & 1 & 0.7 \\
\hline \multicolumn{3}{|c|}{ Birth weight (Bwt*) in kilograms } \\
\hline$<2.5$ & 12 & 7.2 \\
\hline $2.5-3.9$ & 96 & 57.5 \\
\hline$>=4.0$ & 59 & 35.3 \\
\hline \multicolumn{3}{|c|}{ Time from delivery to IUD insertion (in minutes) } \\
\hline$<=10$ & 75 & 45.2 \\
\hline $15-59$ & 28 & 16.9 \\
\hline$>=60$ & 63 & 37.9 \\
\hline Median & $20(\mathrm{IQR}, 10-285)$ & \\
\hline \multicolumn{3}{|l|}{ Menstrual flow } \\
\hline Heavy & 7 & 4.2 \\
\hline Normal & 157 & 94 \\
\hline Scanty & 3 & 1.8 \\
\hline \multicolumn{3}{|l|}{ Associated cramps } \\
\hline Yes & 60 & 35.9 \\
\hline No & 107 & 64.1 \\
\hline \multicolumn{3}{|c|}{ Ever used Intrauterine Device } \\
\hline Yes & 11 & 6.6 \\
\hline No & 156 & 93.4 \\
\hline
\end{tabular}

IQR Inter-quartile range, IUD Intra-uterine device; Bwt*: Mean, $3.3 \mathrm{~kg}(\mathrm{SD} \pm 0.6)$. 
Table 2 Postnatal characteristics of study participants $(N=144)$

\begin{tabular}{lll}
\hline Characteristic & Frequency & Percentage \\
\hline Resumption of sexual activities & \\
Yes & 74 & 51.4 \\
No & 70 & 48.6 \\
Return of menses & 13 & 9 \\
Yes & 131 & 91 \\
No & & \\
Tummy tying & 70 & 48.6 \\
Yes & 74 & 51.4 \\
No & & \\
Vaginal douching & 18 & 12.5 \\
Yes & 126 & 87.5 \\
No & & \\
Use of herbs & 22 & 15.3 \\
Yes & 122 & 84.7 \\
No & 18 & 12.5 \\
Resumption of heavy physical activity & 88.5 \\
Yes & 126 & \\
No & & \\
\hline
\end{tabular}

\section{Discussion}

The expulsion rate of $9 \%$ observed in our prospective study is consistent with findings from several studies that have reported expulsion rates that range from 5 to $15 \%$ [23-27]. A lower expulsion rate of 3.8\% than ours was reported in India, probably because the study in India relied on self-report of IUD expulsion, and therefore subjectively determined. In our study we used both clinical exam and sonographic criteria to ascertain IUD expulsion. Higher expulsion rates of 17 and 16\% have been reported in USA [28] and Mexico [19] respectively. The possible reason for the higher expulsion rates in these studies than ours, could be because of the longer follow-up time of 3 to 6 months. In our study, we followed up women for only 6 weeks postpartum. Similarly, higher expulsion rates than ours have been observed in studies that used levonorgestrel IUD [17, 29]. The higher expulsion rates of levonorgestrel IUD may possibly be attributed to the use of levonorgestrelreleasing IUD inserter for postplacental insertions, as opposed to our study in which we used ring forceps for IUD insertions, and therefore had higher chances for high fundal placement [30]. To decrease IUD expulsion rates, high fundal placement is recommended [30, 31].

The expulsion rate in the current study is comparable to that observed in interval IUD insertions. This has important implications for family planning uptake and reproductive health in Uganda. Given that Uganda has a high unmet need for family planning [5, 32], there is need to emphasize prenatal counseling for postpartum
Table 3 Risk factors for PPIUD expulsion

\begin{tabular}{|c|c|c|c|}
\hline \multirow[b]{2}{*}{ Variable } & \multirow{2}{*}{$\begin{array}{l}\text { Unadjusted analysis } \\
\text { RR }(95 \% \mathrm{Cl})\end{array}$} & \multicolumn{2}{|l|}{ Adjusted analysis } \\
\hline & & Adjusted RR $(95 \% \mathrm{Cl})$ & $p$-value \\
\hline \multicolumn{4}{|l|}{ Age in years } \\
\hline $18-24$ & 1 & & \\
\hline $25-34$ & $1.18(0.22-6.16)$ & & \\
\hline$\geq 35$ & $2.79(0.49-15.62)$ & & \\
\hline \multicolumn{4}{|c|}{ Education Level } \\
\hline None & 1 & & \\
\hline Primary & $0.88(0.091-8.646)$ & & \\
\hline Secondary & $1.00(0.102-9.75)$ & & \\
\hline Tertiary & $0.44(0.035-5.522)$ & & \\
\hline \multicolumn{4}{|c|}{ Birth weight (in kilograms) } \\
\hline$<2.5$ & 1 & & \\
\hline $2.5-3.9$ & $0.36(0.35-3.71)$ & & \\
\hline$\geq 4$ & $1.24(0.13-11.52)$ & & \\
\hline \multicolumn{4}{|l|}{ Parity } \\
\hline Parity 1 & 1 & & \\
\hline Parity 2 & $2.71(0.26-28.37)$ & & \\
\hline Parity3 & $0.65(0.04-11.11)$ & & \\
\hline Parity4 & $0.70(0.04-11.96)$ & & \\
\hline $5 \&$ above & $4.03(0.46-35.29)$ & & \\
\hline
\end{tabular}

Time from delivery to IUD insertion (in minutes)

$\begin{array}{llll}\leq 10 \min & 1 & 1 & \\ 11-59 \min & 8.95(1,61-49.81) & \mathbf{8 . 1 1 ( 1 . 2 6 - 5 1 . 9 8 )} & \mathbf{0 . 0 2 7} \\ \geq 60 \text { min } & 4.86(0.94-25.19) & 4.78(0.86-26.43) & 0.070\end{array}$

Duration of menses in days

$\leq 3$

$4 \quad 1$

$>=5 \quad 1.23(0.34-4.49)$

Past IUD use $1.61(0.35-7.30)$

No 1

Yes $\quad 1.1(0.13-9.53)$

Resumption of sex

No 1

Yes $\quad 3.60(0.95-13.69)$

Duration of bloody lochia flow in days

\begin{tabular}{|c|c|c|c|}
\hline $0-7$ & 1 & 1 & \\
\hline 8 to 14 & $1.91(0.48-7.53)$ & $1.35(0.33-5.53)$ & 0.924 \\
\hline$\geq 15$ & $7.37(1.45-37.45)$ & 8.45 (1.47-48.47) & 0.017 \\
\hline
\end{tabular}

family planning as this will facilitate postplacental IUD uptake. In addition, the Ministry of Health should consider conducting in-service training of all health personnel who conduct deliveries, in postplacental IUD insertions, so as to ensure 24-h availability of the service providers with skills to insert postplacental IUDs. 
In this study, the time lag from delivery to IUD insertion and duration of lochia flow were significantly associated with postpartum IUD expulsion, in agreement with previous findings $[15,21,28]$. We found that women who had IUDs inserted 11-59 min after delivery had a higher risk than those who had the IUDs inserted within 10 min post-delivery. This could be explained by the fact that within $10 \mathrm{~min}$ of delivery, the cervix is still fully open, making placement of the IUD high in the uterine fundus much easier compared to insertion at a later time [15]. This finding further underscores the need for routine prenatal counselling of women on post-partum post placental IUD insertions to reduce on expulsion rates associated with late insertions.

Women who experienced bloody lochia flow for 15 or more days had higher risk for IUD expulsion compared to their counterparts who experienced fewer days of bloody lochia flow. This is probably due to the fact that bloody lochia flow is associated with increased uterine contractions, which may be induced by the presence of a foreign body in the uterus [33], and this may lead to IUD expulsion. Although this association is a new finding, these data call for ensuring that women who experience prolonged bloody lochia flow following postpartum IUD insertion, be encouraged to return early for follow up (within 6 weeks), in order to detect any spontaneous expulsion.

\section{Limitations}

Our study has some limitations worth mentioning. First, the main limitation for our study is loss to follow-up. Twenty-three (14\%) of the 167 participants were lost to follow-up. Nevertheless, the retention rate was good enough (86\%) not to affect the power of the study. In addition, there was no statistically significant difference in the baseline characteristics of participants who were lost to follow-up and those who were retained in the study. Second, our followup period of 6 weeks was relatively shorter compared to what is reported in background literature [9]. We recommend further longitudinal studies, with longer follow-up periods for PPIUD expulsions in our setting in Uganda. Finally, we used only CuT380A IUDs in our study because they are the ones recommended for use for PPIUD insertions, by the Ministry of Health in Uganda. Therefore, our findings may not be generalizable beyond the population of women using CuT380A IUDs, such as those using Levonorgestrel IUDs. The major strengths of our study lie in its prospective nature and the fact that we objectively assessed expulsion of PPIUDs using both clinical examinations and ultrasound scan when clinically indicated.

\section{Conclusion}

In conclusion, the cumulative expulsion rate of postpartum IUD among women delivering at MRRH was low and comparable to expulsion rates in interval IUD insertions. Delayed time from delivery to IUD insertion and prolonged duration of bloody lochia flow were the key risk factors for postpartum IUD expulsion during puerperium, among women delivering at MRRH in southwestern Uganda. Our findings support routine prenatal counseling for postpartum family planning to allow for post-placental IUD insertions, which are associated with lower expulsion rates.

\section{Abbreviations}

aRR: Adjusted risk ratio; Cl: Confidence interval; FRC: Faculty Research Committee; IQR: Interquartile range; IUD: Intrauterine device; MRRH: Mbarara Regional Referral Hospital; MSI: Marie stopes International; MUST: Mbarara University of Science and Technology; PPH: Postpartum hemorrhage; PPIUD: Postpartum intrauterine device; PSI: Population Services International; REC: Research Ethics Committee; RR: Risk ratio; SD: Standard deviation; WHO: Word Health Organization

\section{Acknowledgements}

The authors are grateful to the study participants, the staff and management of Mbarara Regional Referral Hospital who provided support during the study period. We are very thankful to our research assistants (Sr.Naiga Patience and Sr. Kibesigire Scondinah). We also acknowledge Dr. Daniel Atwiine and Dr. Ronald Mayanja (R.I.P) for their technical input into the study.

\section{Authors' contributions}

J.M., M.K., G.M., R.M., and J.N., contributed conception of the study, wrote, reviewed and edited the manuscript. R. M and J. M analyzed the data. G.M., M.K., and J.N. supervised the research. All authors read and approved the final manuscript.

\section{Funding}

This study received sponsorship from Massachusetts General Hospital (MGH). The sponsors of the study had no role in the study design, data collection, data analysis nor interpretation.

\section{Availability of data and materials}

The datasets generated and analyzed during the study are available from the 1 st author upon reasonable request.

\section{Ethics approval and consent to participate}

We received approval to conduct this study from the institutional ethics review board of Mbarara University of Science and Technology (MUST-REC) and the Faculty of Medicine Research Committee (FRC). The study was given approval number 04/09-14 by the MUST-REC. All study participants provided written informed consent before recruitment and participation into the study. Participants who could not write gave consent with a thumbprint. Participants who had expulsion of IUDs were linked to family planning clinic to have a family planning method of their choice.

\section{Consent for publication}

Not applicable.

\section{Competing interests}

The authors declare no competing interests in regard publication of this work.

\section{Author details}

'Department of Obstetrics and Gynecology, Mbarara University of Science and Technology, Mbarara, Uganda. ${ }^{2}$ Department of Obstetrics and Gynecology, Kampala International University, Kampala, Uganda.

${ }^{3}$ Department of Physiology, Mbarara University of Science and Technology, P.O Box 1410, Mbarara, Uganda. 
Received: 6 July 2020 Accepted: 5 February 2021

Published online: 02 March 2021

\section{References}

1. Makins A, Arulkumaran S. Institutionalization of postpartum intrauterine devices. Int J Gynaecol Obstet. 2018;143(Suppl 1):1-3

2. Darroch JE, Sully E, Biddlecom A. Adding it up: investing in contraception and maternal and newborn health, 2017-supplementary tables. New York: The Guttmacher Institute; 2017.

3. Gribble J, Haffey J. Reproductive health in sub-Saharan Africa. Population Reference Bureau; 2008. p. 8

4. Clifton D, Kaneda T, Ashford L. Family planning worldwide 2008 data sheet. Washington: Population Reference Bureau; 2008. p. 15.

5. UBOS I. Uganda demographic and health survey 2011. Kampala and Claverton: Uganda Bureau of Statistics and ICF International Inc.; 2012.

6. Pollack A, GP J. Intrauterine devices (IUDs) in developing countries: assessing opportunities for expanding access and use. Assessment prepared for the Hewlett Foundation population Program; 2006.

7. Winner B, Peipert JF, Zhao Q, Buckel C, Madden T, Allsworth JE, et al. Effectiveness of long-acting reversible contraception. N Engl J Med. 2012; 366(21):1998-2007.

8. Organization $\mathrm{WH}$, Health WHOR. Medical eligibility criteria for contraceptive use: World Health Organization; 2010

9. Grimes DA, Lopez LM, Schulz KF, Van Vliet HA, Stanwood NL. Immediate post-partum insertion of intrauterine devices. Cochrane Database Syst Rev. 2010:5:CD003036.

10. Organization $\mathbf{W H}$. Report of a $\mathbf{W H O}$ technical consultation on birth spacing: Geneva, Switzerland 13-15 June 2005: World Health Organization; 2007.

11. Mohamed SA, Kamel MA, Shaaban OM, Salem HT. Acceptability for the use of postpartum intrauterine contraceptive devices: Assiut experience. Med Princ Pract. 2003;12(3):170-5.

12. Arulkumaran S, Hediger V, Manzoor A, May J. Group MHW. In: Saving Women' lives: transforming strategy into action: report of the maternal health working group 2012: Global Health policy summit; 2012.

13. Vlassoff M, Sundaram A, Bankole A, Remez L, Mugisha F. Benefits of meeting the contraceptive needs of Ugandan women. Issues Brief (Alan Guttmacher Institute). 2009;4:1-8

14. Borda MR, Winfrey W, McKaig C. Return to sexual activity and modern family planning use in the extended postpartum period: an analysis of findings from seventeen countries. Afr J Reprod Health. 2010;14(4):72.

15. Morrison C, Waszak C, Katz K, Diabaté F, Mate E. Clinical outcomes of two early postpartum IUD insertion programs in Africa. Contraception. 1996; 53(1):17-21.

16. Hayes JL, Cwiak C, Goedken P, Zieman M. A pilot clinical trial of ultrasoundguided postplacental insertion of a levonorgestrel intrauterine device. Contraception. 2007;76(4):292-6.

17. Goldthwaite LM, Sheeder J, Hyer J, Tocce K, Teal SB. Postplacental intrauterine device expulsion by 12 weeks: a prospective cohort study. Am J Obstet Gynecol. 2017;217(6):674.e1-8.

18. Shukla M, Sabuhi Qureshi C. Post-placental intrauterine device insertion-a five year experience at a tertiary care Centre in North India. Indian J Med Res. 2012;136(3):432

19. RosalesaFB, Zamudio MEA, Montero MdLC, Ortiz MEH, Ruiz MÁL. Factors for expulsion of intrauterine device Tcu380A applied immediately postpartum and after a delayed period. Revista médica del Instituto Mexicano de Seguro Social 2005;43(1):5-10.

20. Müller ALL, Ramos JGL, Martins-Costa SH, Dias RSP, Valério EG, Hammes LS, et al. Transvaginal ultrasonographic assessment of the expulsion rate of intrauterine devices inserted in the immediate postpartum period: a pilot study. Contraception. 2005:72(3):192-5.

21. Eroğlu K, Akkuzu G, Vural G, Dilbaz B, Akın A, Taşkın L, et al. Comparison of efficacy and complications of IUD insertion in immediate postplacental/ early postpartum period with interval period: 1 year follow-up. Contraception. 2006:74(5):376-81.

22. MRRH. Mbarara Regional Referral Hospital (MRRH) Annual Report-2012/2013. In: Obstetrics and Gynecology, editor. Mbarara 2014

23. Colwill AC, Schreiber CA, Sammel MD, Sonalkar S. Six-week retention after postplacental copper intrauterine device placement. Contraception. 2018; 97(3):215-8
24. Gurney EP, Sonalkar S, McAllister A, Sammel MD, Schreiber CA. Six-month expulsion of postplacental copper intrauterine devices placed after vaginal delivery. Am J Obstet Gynecol. 2018;219(2):183. e1-9.

25. Bhattacharya P, Linyu K, Chakraborty S. Acceptability, Uptake and safety of post-partum intrauterine contraceptive device: a case study. Population Dynamics in Eastern India and Bangladesh: Springer; 2020. p. 105-13.

26. Spagnolo A, Giussani M, Ambruzzi AM, Bianchetti M, Maringhini S, Matteucci $M C$, et al. Focus on prevention, diagnosis and treatment of hypertension in children and adolescents. Ital J Pediatr. 2013;39(1):20.

27. Çelen Ş, Möröy P, Sucak A, Aktulay A, Danışman N. Clinical outcomes of early postplacental insertion of intrauterine contraceptive devices. Contraception. 2004;69(4):279-82

28. Jatlaoui TC, Marcus M, Jamieson DJ, Goedken P, Cwiak C. Postplacental intrauterine device insertion at a teaching hospital. Contraception. 2014 89(6):528-33.

29. Chen BA, Reeves MF, Hayes JL, Hohmann HL, Perriera LK, Creinin MD. Postplacental or delayed insertion of the levonorgestrel intrauterine device after vaginal delivery: a randomized controlled trial. Obstet Gynecol. 2010; 116(5):1079.

30. O'Hanley K, Huber DH. Postpartum IUDs: keys for success. Contraception. 1992;45(4):351-61.

31. Stumpf PG, Lenker RM. Insertion technique, not design, affects expulsion rates of postpartum intrauterine device. Contraception. 1984;30(4):327-30.

32. Statistics UBo ICF. Uganda demographic and health survey 2016: key indicators report. UBOS. In: And Rockville Maryland; 2017

33. Sheppard BL. Endometrial morphological changes in IUD users: a review. Contraception. 1987;36(1):1-10.

\section{Publisher's Note}

Springer Nature remains neutral with regard to jurisdictional claims in published maps and institutional affiliations.

Ready to submit your research? Choose BMC and benefit from:

- fast, convenient online submission

- thorough peer review by experienced researchers in your field

- rapid publication on acceptance

- support for research data, including large and complex data types

- gold Open Access which fosters wider collaboration and increased citations

- maximum visibility for your research: over $100 \mathrm{M}$ website views per year

At $\mathrm{BMC}$, research is always in progress.

Learn more biomedcentral.com/submissions 